\title{
Physiochemical Stability of Intravenous Fat Emulsion in Combination with Medications Used for Resuscitation
}

\author{
Craig Cocchio $^{1 *}$, Ann-Jeannette Geib ${ }^{1}$ and Kevin 0 Rynn ${ }^{2}$ \\ ${ }^{1}$ Ernest Mario School of Pharmacy, The State University of New Jersey Robert Wood Johnson University Hospital, New Brunswick, United States \\ ${ }^{2}$ Rosalind Franklin University of Medicine and Science, North Chicago, Illinois, United States
}

Received: October 24, 2013; Accepted: February 06, 2014; Published: February 07, 2014

*Corresponding author: Craig Cocchio, Ernest Mario School of Pharmacy, The State University of New Jersey Robert Wood Johnson University Hospital, New Brunswick, United States, Tel: 201-344-5279; E-mail: cocchio@pharmacy.rutgers.edu

\begin{abstract}
Objective: Intravenous fat emulsion (IFE) is a potential therapy for lipophilic drug overdose. IFE stability with drugs commonly used in resuscitation has not been assessed. This study's purpose is to examine the in vitro physiochemical stability of various combinations of IFE and medications commonly used in resuscitation by measuring the proportion of enlarged droplets greater than 5 micrometers (PFAT5) in IFE after mixture.

Methods: We compared, in vitro, PFAT5 in various IFE-medication mixtures and a control (IFE alone). In order to assess the degree of coalescence, globule-size distribution was assessed according to method II of United States Pharmacopeia (USP) chapter 729. IFE was mixed in a 1:1 ratio with standard concentrations of medications. IFE- medication mixtures with PFAT5 $>0.05 \%$ at time 0 and 1 hour were considered coalesced. If any results of method II exceeded PFAT5 of the control, analysis of the globule-size distribution data was conducted using a one tailed Student's T test with a level of significance set at $\mathrm{p}<0.05$.

Results: At time zero, the PFAT5 of calcium chloride $(\mathrm{p}<0.001)$, dextrose $50 \%(p=0.03)$, glucagon $(p<0.001)$, lidocaine $(p=0.001)$, magnesium sulfate $(\mathrm{p}=0.02)$ and sodium bicarbonate $(\mathrm{p}<0.001)$ were significantly higher compared to control. At time 1 hour the PFAT5 of, amiodarone $(p=0.02)$, calcium chloride $(p<0.001)$, D50W $(p<0.001)$, epinephrine $(\mathrm{p}<0.001)$, glucagon $(\mathrm{p}<0.001)$, insulin regular $(\mathrm{p}<0.001)$, magnesium sulfate $(\mathrm{p}<0.001)$, naloxone $(\mathrm{p}=0.02)$, sodium bicarbonate $(\mathrm{p}=0.01)$ and vasopressin $(\mathrm{p}<0.001)$ were significantly higher compared to control.
\end{abstract}

Conclusion: IFE should be administered in a separate administration line when given with these medications.

Keywords: Lipid emulsion; Lipid bolus; Overdose; Compatibility

\section{Introduction}

Medications used to treat chronic cardiovascular diseases are increasingly being associated with toxic exposures reported to American Poison Control Centers. Outpaced only by analgesics and sedatives/hypnotics/antipsychotics, cardiovascular medications present unique challenges to clinicians when treating overdose patients since no specific antidote is available [1]. While supportive care is a cornerstone of treatment, novel therapies such as hyperinsulenemia-euglycemia (HIE), glucagon or intravenous fat emulsion (IFE) therapy, are often utilized. However, there is still a need for a specific reversal agent. IFE is a potential therapy for lipophilic drug overdose and is an emerging therapy for toxicology emergencies. Intralipid $\AA$, a commonly used commercially available IFE product, has shown promising outcomes in animal models exposed to lipophilic cardiotoxic medications and numerous case reports of toxic exposures to these medications in humans [2]. Althoughutilization of IFE in its traditional parenteral nutrition setting requires careful considerations to avoid disrupting the oil - in-water emulsion leading to fat emboli, similar considerations should be taken when administration occurs in a toxicologic emergency. Known factors that can compromise the emulsion include rapid administration, concomitant administration of divalent or trivalent electrolytes, and acidic $\mathrm{pH}$ [3-5]. During toxicologic emergencies, these factors may be encountered, resulting in increased risk for the emulsion being disrupted or coalesced, creating larger fat globules. Standards to identify safe globule size distribution in IFE products can be found in the United States Pharmacopeia, Chapter 729 (USP) [6]. While the size characteristics of IFE include the mean diameter of the lipid droplets and the range of the various droplet diameters, with respect to infusion safety, the amount of fat globules that encompass the large-diameter tail are most important. The USP chapter 729 describes two methods: lightscattering method for determining mean droplet size of lipid emulsions, and light obscuration or extinction for measurement of large globule content.

There are however, non-optical method for counting and sizing particles of all types. Electrical sensing zone method utilizes electrical impedance to measure the volume of a particle and the height of the electric pulse generated from passage of the particle through a small aperture. This measurement technique results in simultaneous analysis of particle concentration and size. In addition, compared to optical measurement techniques, the measurement by electrical sensing zone method is not affected by color, shape, and optical characteristics of particles [7]. This technique may represent an alternative method for determining globule-size of IFE products and admixtures. 
Compatibility data of IFE when exposed to various medications administered in resuscitation and toxicologic emergencies are lacking [3]. Therefore, the purpose of this study is to examine the in vitro physiochemical stability of various combinations of IFE and medications commonly used in resuscitation.

\section{Methods}

We conducted a physiochemical compatibility study in a $y$-site administration model where IFE (Intralipid ${ }^{\circledR}$ ) was mixed in a 1:1 ratio with standard concentrations of medications [8]. This concentration was selected because it would mirror the clinical scenario in which the medications tested would be administered through the same intravenous line. Each medication and the concentration used can be found in Table 1 . All medications, except for glucagon and norepinephrine, were used in their commercially available intravenous solutions and concentrations that would be administered as such in patient resuscitation scenarios. Glucagon, was reconstituted with $1 \mathrm{~mL}$ of sterile water for injection, and norepinephrine was diluted with dextrose $5 \%$. Each sample was assessed once. The primary objective of this study was to compare in vitro the proportion of fat emulsion particle size greater than 5 micrometers in various IFE-medication mixtures and a control of IFE and sodium chloride $0.9 \%$ (normal saline).

The degree of coalescence of this mixture was measured via globule-size distribution assessment according USP chapter 729 [6], assessing the large-diameter tail, expressed as the volume-weighted percent of fat greater than 5 micrometers (PFAT5). Consistent with USP chapter 729, an IFE is considered coalesced with PFAT5 values greater than $0.05 \%$. Therefore, IFEmedication mixtures with PFAT5 values greater than $0.05 \%$ at time 0 and 1 hour were considered coalesced. Samples exceeding PFAT5 of the control, were compared using a Student's T test with an alpha level of significance set at $p<0.05$. In this study, PFAT5 values were obtained with a Beckman-Coulter Multisizer 3 automated particle counter.

\section{Results}

All samples tested including the normal saline control contained a concentration of particles of greater than 5 micrometers that exceeded $0.05 \%$, thereby exceeding the PFAT5 upper limit set by USP chapter 729 . When compared to the control at time zero, the PFAT5 of calcium chloride $(p<0.001)$, dextrose $50 \%(p=0.03)$, glucagon $(p<0.001)$, lidocaine $(p=0.001)$, magnesium sulfate $(\mathrm{p}=0.02)$ and sodium bicarbonate $(\mathrm{p}<0.001)$ were significantly higher (Table 1 ).

At time 1 hour the PFAT5 of, amiodarone $(\mathrm{p}=0.02)$, calcium chloride $(\mathrm{p}<0.001)$, dextrose $50 \% \quad(\mathrm{p}<0.001)$, epinephrine $(\mathrm{p}<0.001)$, glucagon $(\mathrm{p}<0.001)$, insulin regular $(\mathrm{p}<0.001)$, magnesium sulfate $(p<0.001)$, naloxone $(p=0.02)$, sodium bicarbonate $(p=0.01)$ and vasopressin $(p<0.001)$ were significantly higher compared to control (Table 1).

Visual coalescence was observed with the glucagon sample at time 0 and 1 hour, and vasopressin at time 1 hour.
Table 1: Intravenous lipid emulsion and medication admixture PFAT5 findings at time 0 and time 1 hour.

\begin{tabular}{|c|c|c|c|c|}
\hline Medication & $\begin{array}{l}\text { PFAT5 } \\
\text { Time 0 } \\
\text { hour }\end{array}$ & $\begin{array}{l}P \\
\text { value }\end{array}$ & $\begin{array}{l}\text { PFAT5 } \\
\text { Time 1 } \\
\text { hour }\end{array}$ & $\begin{array}{l}P \\
\text { value }\end{array}$ \\
\hline $\begin{array}{l}\text { Normal saline } 0.9 \% \\
\text { (control) }\end{array}$ & 0.10 & N/A & 0.18 & $\mathrm{~N} / \mathrm{A}$ \\
\hline Adenosine $(3 \mathrm{mg} / \mathrm{mL})$ & 0.09 & N/A & 0.25 & 0.054 \\
\hline Amiodarone $(30 \mathrm{mg} / \mathrm{mL})$ & 0.12 & 0.38 & 0.26 & 0.02 \\
\hline Atropine $(0.1 \mathrm{mg} / \mathrm{mL})$ & 0.14 & 0.11 & 0.20 & 0.49 \\
\hline $\begin{array}{l}\text { Calcium chloride }(100 \mathrm{mg} / \\
\mathrm{mL})\end{array}$ & 0.41 & $<0$ & 0.68 & $\begin{array}{l}< \\
0.001\end{array}$ \\
\hline Dextrose $50 \%(50 \mathrm{mg} / \mathrm{mL})$ & 0.15 & 0.03 & 0.37 & $\begin{array}{l}< \\
0.001\end{array}$ \\
\hline Epinephrine $(0.1 \mathrm{mg} / \mathrm{mL})$ & 0.08 & N/A & 0.42 & $\begin{array}{l}< \\
0.001\end{array}$ \\
\hline Glucagon (1 mg/mL) & 1.17 & $\begin{array}{l}< \\
0.001\end{array}$ & 1.69 & $\begin{array}{l}< \\
0.001\end{array}$ \\
\hline Insulin regular (1 unit/mL) & 0.11 & 0.11 & 0.70 & $\begin{array}{l}< \\
0.001\end{array}$ \\
\hline Lidocaine (10 mg/mL) & 0.19 & 0.001 & 0.20 & 0.41 \\
\hline $\begin{array}{l}\text { Magnesium sulfate }(50 \mathrm{mg} / \\
\mathrm{mL})\end{array}$ & 0.15 & 0.02 & 0.37 & $\begin{array}{l}< \\
0.001\end{array}$ \\
\hline Naloxone $(0.4 \mathrm{mg} / \mathrm{mL})$ & 0.08 & $\mathrm{~N} / \mathrm{A}$ & 0.25 & 0.02 \\
\hline $\begin{array}{l}\text { Norepinephrine }(0.032 \mathrm{mg} / \\
\mathrm{mL})\end{array}$ & 0.12 & 0.18 & 0.18 & 0.45 \\
\hline $\begin{array}{l}\text { Sodium bicarbonate (10 } \\
\mathrm{mEq} / \mathrm{mL} \text { ) }\end{array}$ & 0.18 & $\begin{array}{l}< \\
0.001\end{array}$ & 0.30 & $\begin{array}{l}< \\
0.001\end{array}$ \\
\hline Vasopressin (40 units/ mL) & 0.11 & 0.28 & 0.42 & $\begin{array}{l}< \\
0.001\end{array}$ \\
\hline
\end{tabular}

PFAT5: Percent of fat greater than 5 micrometers, measured in \%

\section{Discussion}

According to data from the American Association of Poison Control Centers, in 2010 there were approximately 2.4 million exposures to poisons reported. ${ }^{1}$ Sedative hypnotics/ antipsychotics, and cardiovascular drugs (i.e., verapamil, or diltiazem) ranked number one and two, respectively, in number of fatal exposures [1].

Many of these common chronic medications have no specific antidote currently available. IFE, a potential therapy for lipophilic drug overdose, is an emerging therapy for toxicology emergencies when other therapies have failed [2].

First applied in parenteral nutrition, IFE products have expanded their spectrum to include local anesthetic toxicity and lipophilic drug overdose. The utilization of IFE emerged after a case report of a female patient who ingested multiple medications followed by successful resuscitation shortly after IFE administration [9]. Following this case report, support of this therapy began to grow for other lipophilic cardiotoxic medication overdose $[10,11]$. As utilization of IFE continues to grow for this "off-label" use, safety, including stability of the pharmacologic properties of this emulsion, should be considered.

Commercially available IFEs such as Intralipid ${ }^{\circledR}$, are an oil-inwater emulsion consisting of one or more triglyceride containing 
oils, a phospholipid emulsifying agent and glycerin [4]. The phospholipid emulsifying agent is a very important component of the stability of the emulsion [5].

Since the polar ends are oriented outwards, an anionic charge is created causing repulsive forces that prevent coalescing of emulsion particles to form larger droplets. The anionic charge can be compromised by a number of factors, including divalent cations (ex. magnesium and calcium), and an acidic $\mathrm{pH}$ of less than 5 [3-5]. If coalescing should occur as a result of co-administering these divalent cations in a resuscitation effort with IFE, fat emboli may be produced leading to pulmonary embolism and potentially fatal consequences.

As of December 1, 2007, the United States Pharmacopeia has established globule-size limits for all commercial intravenous nutritional lipids in chapter 729 [6]. Two key methods of globulesize distribution have been described. Method I is a measure of the mean droplet diameter, expressed as the intensity- weighted mean droplet diameter in nanometers. Method II assesses the large-diameter tail, expressed as the volume-weighted PFAT5. The globule size parameters are set based on blood vessel physiology and anatomy, as well as evidence suggesting particles greater than 5 micrometers are large enough to occlude small capillaries and risk of pulmonary embolism [12]. Although this study utilized non- optical method for counting and sizing particles, future studies should compare the results of this study with analysis of globule size using light-scattering, light obscuration or extinction techniques.

Although data exists with regard to IFE stability with cations in concentrations used for total parenteral nutrition [3], concentrations of IFE and cations used in resuscitation, in addition to different physiological pH has never been assessed until this study.

IFE and concentrations of electrolytes, such as calcium and sodium, used in total parenteral nutrition are often regarded as pharmaceutically compatible [3]. However, in resuscitation scenarios much higher concentrations of electrolytes, such as calcium and sodium used, and may pose a higher risk of compromising the IFE. As observed in this study, these higher concentrations of electrolytes significantly increase the concentration of particles of greater than 5 micrometers, thereby exceeding the PFAT5 upper limit set by USP chapter 729 [6].

The control IFE sample tested in this study, contained a concentration of particles of greater than 5 micrometers that exceeded $0.05 \%$, thereby exceeding the PFAT5 upper limit set by USP chapter 729 [6]. While this finding has been reported elsewhere [13], confirmation of this finding utilizing Method I was not conducted. When compared to the control, standard concentrations and doses of calcium chloride, dextrose 50\%, glucagon, lidocaine, magnesium sulfate, and sodium bicarbonate created a statistically significantly higher PFAT5 immediately after mixing.

.This study is limited, however, because we did not assess the stability of IFE using Method I due to lack of required equipment. Comparison of this data with results from Method I would help identifying medications that are safe to administer with IFE. Also unknown are the effects of IFE disruption due to these medications in vivo. Future studies should assess not only for the effects of IFE on the ingested medications but also any complications that may be attributed to IFE administration.

\section{Conclusion}

In summary, this data suggests that IFE should be administered in a separate administration line when given with any of these medications listed in Table 1 . However, the clinical implications of these medications disrupting IFE stability are unknown and warrant further investigation.

\section{References}

1. Bronstein AC, Spyker DA, Cantilena LR, Green JL, Rumack BH, et al. (2011) 2010 Annual Report of the American Association of Poison Control Centers' National Poison Data System (NPDS): $28^{\text {th }}$ Annual Report. Clin Toxicol 49: 910-941.

2. Ozcan MS, Weinberg G (2012) Intravenous Lipid Emulsion for the Treatment of Drug Toxicity. J Intensive Care Med.

3. Trissel L (2005) Handbook on injectable drugs. ( $13^{\text {th }}$ edn), American Society of Health-System Pharmacists $®$, Bethesda, USA.

4. (2007) Intralipid( ${ }^{\circledR} \quad 20 \%$ [Package Insert]. Baxter Healthcare Corporation, Deerfield, IL

5. Mirtallo JM, Dasta JF, Kleinschmidt KC, Varon J. (2010) State of the art review: Intravenous fat emulsions: current applications, safety profile, and clinical implications. Ann Pharmacother 44: 688-700

6. (2007) Globule size distribution in lipid injectable emulsions. In: The United States pharmacopeia and the national formulary, $\left(25^{\text {th }}\right.$ edn $)$, United States Pharmacopeial Convention Rockville, MD, pp. 39683970.

7. Application notes: Quality control of injectable fat emulsion using a Coulter Counter ${ }^{\circ}$.

8. Allen LV, Levinson RS, Phisutsinthop D (1977) Compatibility of various admixtures with secondary additives at Y-injection sites of intravenous administration sets. Am J Hosp Pharm 34: 939-943.

9. Sirianni AJ, Osterhoudt KC, Calello DP, Muller AA, Waterhouse MR, et al. (2008) Use of Lipid Emulsion in the Resuscitation of a Patient With Prolonged Cardiovascular Collapse After Overdose of Bupropion and Lamotrigine. Ann Emerg Med 51: 412-415.

10.American College of Medical Toxicology (2011) ACMT position statement: interim guidance for the use of lipid resuscitation therapy. J Med Toxicol 7: 81-82.

11.Weinberg GL (2012) Lipid emulsion infusion: resuscitation for local anesthetic and other drug overdose. Anesthesiology 117: 180-187.

12. Driscoll DF, Thoma A, Franke R, Klütsch K, Nehne J, et al.(2009). Lipid globule size in total nutrient admixtures prepared in three-chamber plastic bags. Am J Health Syst Pharm 66: 649-656.

13. Driscoll DF (2007) Globule-size distribution in injectable 20\% lipid emulsions: Compliance with USP requirements. Am J Health-Syst Pharm 64: 2032-2036. 